\title{
Self-Disclosure and SNS Addiction in South Asian Youth: An Empirical Study of Pakistan
}

\author{
Shamsa Kanwal ${ }^{1}$, Ren Chong ${ }^{1}$, Abdul Hameed Pitafi ${ }^{2}$, Haque Nawaz ${ }^{3}$ \\ ${ }^{1}$ School of Public Affairs, University of Science and Technology of Hefei, Hefei, China \\ ${ }^{2}$ School of Management, University of Science and Technology of Hefei, Hefei, China \\ ${ }^{3}$ Department of Computer Science, Sindh Madressatul Islam University, Karachi, Pakistan
}

Email address:

shamsa@mail.ustc.edu.cn(S. Kanwal),renchong@ustc.edu.cn(Ren Chong), hameedpitafi@hotmail.com(A. H. Pitafi), lashari.haquenawaz@gmail.com(H.Nawaz)

\section{To cite this article:}

Shamsa Kanwal, Ren Chong, Abdul Hameed Pitafi, Haque Nawaz. Self-Disclosure and SNS Addiction in South Asian Youth: An Empirical Study of Pakistan. Advances in Sciences and Humanities. Vol. 4, No. 1, 2018, pp. 1-11. doi: 10.11648/j.ash.20180401.11

Received: February 16, 2018; Accepted: March 26, 2018; Published: May 4, 2018

\begin{abstract}
Social networking sites (SNS) provide an open platform for communication and interaction and socialization. But the main idea behind this article was to assess the impact of whether SNS addiction effects online self- disclosure or not moreover its mediation impact. The main idea of this study is to investigate the mediating effect of habit, psychological wellbeing, psychological dependence and perceived ease of use between SNS and self-disclosure. Specifically, this research proposes a model to examine how the effect of SNS usage mediates self-disclosure through psychological conditions. Data was collected online using the Google documents application, from university students in Pakistan. In total 338 entries were analyzed and reported, for analysis SPSS version 21 was used. Results show that Pakistani youth tend to have higher selfdisclosure online due to habit, perceived ease of use and while sharing online makes them feel better as the mediator of psychological well-being also reported a positive mediating effect.
\end{abstract}

Keywords: SNS Addiction, Self-disclosure, Psychological Well-Being, Pakistan

\section{Introduction}

During the early years of the Internet, all the websites were passive meaning that the visitors can only visit, read information but were not able to edit or input any information as during these times social networking online wasn't even a concept. The editing privileges in those days belonged to only the website administrators and they were solely responsible for the contents being displayed. In the early days the internet was in an evolving stage and close to no website was available that was working on real-time basis. Thus resulting in a lack of proper user friendly interface and forcing the internet to be only information seeking tool for the masses [1]. In the beginning of 2000s, the websites started new features that enabled users to be able to take participate in the contact of the website. This yielded better internet traffic and users were able to interact to a certain degree with the websites, these types of websites were known as social websites or web $2.0[2,3]$. These initial websites although were limited in the capabilities to interact with the users but were able to exchange contents and create contents [4]. The rapid interest or various factors invested by the transmit the effects of SNS usage were recognized as critical for advancing understanding of this problem. The problem being the excessive usage or rather rapid growth of SNS theme based website did not allow the society to grow with it at the same speed [5]. This rapid difference in growth from SNS and adoption from society resulted in the factors that are nowadays termed as excessive use and having been categorized now as being a disorder. In this study, we studied the mediating effect of habit, psychological well-being, psychological dependence, perceived ease of use on SNS addiction and its impact on self-disclosure.

The term self-disclosure ranges from something simple as updating status, posting content, videos, or broadcasting any information that contains personal information to sharing something as explicit as nudity are treated as self-disclosure [6]. Status update may consist of some personal information such as different daily life events or even exact location 
details i.e. security risks are high for this type of sharing behavior. Self-disclosure can simply be defined as an act or action in which and individual intentionally shares personal information online using SNS and makes himself or herself known to others. Research has shown that the degree of selfdisclosure is assessed by the dimensions depth and breadth such as quality and quantity depth is fundamentally the intimacy level of the disclosure [7], whereas breadth shows the amount of information exchanged. Past research has also shown that SNS can be used by peoples for productive activities, such as to keep a current relationship, make new friends, self-expression, work related activates and educational purpose [8,9]. Nowadays, almost everyone is regularly involved in SNS and this leads to self-disclosure, the alarming situation in SNS exposure is that the audience is unknown if proper checks and balances are not followed [10].

Social networking sites are also a great way to interact with other nationals from various countries. In recent years, the usage of SNS has drastically increased yielding an increased use in Pakistan. In Social networking websites, thousands of users can join at the same time from anywhere around the world and develop an online community. This leads towards, thousands of communities forming on a regular basis online to exchange knowledge, share information, learn about one another's culture and even collaborate on research to maybe in rare occurrence meet their better half [11].

In this study our focus was to go beyond SNS addiction. Thus, leading towards our theoretical framework developing from SNS addiction and taking it as an independent variable. considering four different factors habit, perceived ease of use, psychological well-being, and psychological dependence as proposed mediators between the relationship of SNS addiction and self-disclosure. As the dependent variable SNS addiction has been vastly studied our aim was to study the fallout from this variable and discuss the various mediating effects that influenced online self-disclosure.

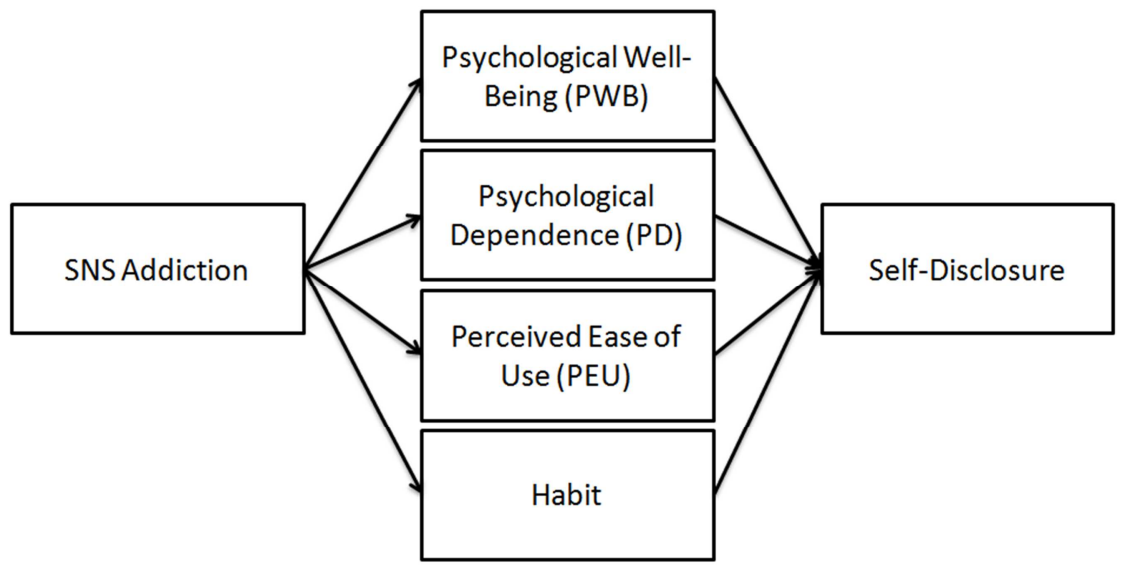

Figure 1. Research Model.

\section{Literature Review and Hypotheses Development}

\subsection{Social Networking Sites Addiction}

In Pakistan, the advent of socializing online started with the use of yahoo messenger in the late 90's. However, the recent growth of social networking websites in Pakistan occurred in the recent years during the advent of websites.i.e. Orkut and Facebook. Social network websites become popular in the Pakistan, unlike the western countries where it has been coined as an addictive behavior. In Pakistan, although the level of usage is high but it has not become a psychological disorder. In particular, SNS addiction can be translated in simple terms as the excessive usage or exceeding amount of time being spent on online social networks. SNS addiction is defined as unnecessary association with SNS activities and is a common cause of problems in everyday social functioning in developed countries whereas it is also on a gradual increase in developing countries like Pakistan [12]. Social networking websites also play an important role in social communication in the twenty first century thus making it an everyday occurrence [13]. In social network websites, users are able to generate a public profile, create social groups, chat with friends and make new friends from across the globe [14]. Meaning that this is an open platform for all communities where everyone connects with friends and other people based on similar interests such as hobbies, games, politics, and education. Individuals describe themselves, updating personal information, profiles, making self-promotion using social network sites, instead of a past time SNS has become a necessity in many forms and circles $[15,16]$. This shows that many users use social websites on daily basis, consuming most of the time in order to maintain online social relations.

The social network websites play a major role in the developing human life in the twenty first century. SNSA is defined as the excess use of the SNS or extreme usage. The personal, social life of human changed with the more interaction of social websites. Due to advancement in technology and continuingly user-friendly interfaces provided by the SNS developer, many people are engaged with online socializing. Therefore, this makes SNS addiction 
as an ideal predictor of over exposure and online selfdisclosure.

\subsection{Self-disclosure}

Self-disclosure on social network sites have some specific properties as compared to self-disclosure in face-to-face communication [6], because self-disclosure on social network sites is usually not associated with a single person, but simultaneously to several people. Hereby an unknown audience can view the posts you have made and build a perception on your personality as an individual.

When someone communicates oneself or shares personal information to others it's known as self-disclosure [17]. It can also be defined as "any information about himself/herself which one person communicates verbally to another person" in face to face communication, however, the same definition applies however the medium changes when its self-disclosure on online websites [18]. Self-disclosure is a real time communication that everyone uses to present themselves to others, i.e. self-presentation or rather in some cases promotion [19]. According to social penetration theory, selfdisclosure is a fundamental concept in developing and maintaining relationships with others. Since basic thinking of human being is to update relationship in any setting be it face-to-face to online. So many people use social networking websites to develop social relationship that evidently leads towards self-disclosure. The more the SNS encourages personalized information the more the individuals are attracted towards these websites, as its human nature that people are interested in learning and getting to know about others, however this behavior also leads towards them disclosing their own personal information without even realizing it in many cases [9].

Due to the success of social networking sites with users increasing at a rapid pace, self-disclosure is only a single implication that needs to be further explained and understood. From a purely psychological perspective selfdisclosure also increases individuals physical and mental health as it provides a sort of self-belief in oneself [9]. This understanding therefore implies that when people share their personal thoughts, feelings to others using social network websites he or she can get psychological benefits as well.

\subsection{The Mediating Effect of Psychological Well-being (PWB)}

Psychological well-being is defined broadly as the positive psychological functioning of an individual [20]. The fundamental thought of psychological well-being denotes to optimal psychological functioning and experience, It's not only focused of everyday interpersonal inquires but also concentrated on technical study as well [21]. Psychological problems have been associated with the addictive behaviors as excessive of anything is considered as bad. It is related with gladness and positive effect and is often discussed as a reflection of overall life happiness and worthiness. Psychological well- being can also be defined as the symbol of state in which a fully effective individual values $\mathrm{him} /$ herself [21]. Previous research specifies that individual's state of well-being may be influenced by his or her feelings, actions, and emotions, as well as by outside experiences [22]. People who have experience of psychological well-being also report engaging in positive behaviors such as social relationship and self-motivation both online and offline in face-to-face interactions. Psychological well-being plays an important role in SNS usage as in the competitions of how many likes one gets on a post to how many people one has as online friends [23]. Interpersonal relations are also affected by SNS self-disclosure as exposing oneself and ones relationships puts at risk all involved [24].

Whereas, to a certain extent psychological well-being can also be improved by social network sites as these platforms provide a feeling of being wanted and heard and give the necessary outlet to express oneself leading almost certainly to self-disclosure. The fundamental objective and excitements for using social network sites are to establish and update online and offline social relationships with others and to inform on oneself as to the day to day happenings. People consume more time on social networking sites for different activities such as chatting, messaging, posting news, this shows that they are increasingly motivated towards exchanges that occur in an online setting on social networks [24]. Current research on social networks shows that individuals dedicate themselves to social networking instead of face-to-face communication because it's useful and can be used to develop relationships even though they are online [25]. To a certain degree interaction on social networks creates enjoyment and happiness as an update of a like gives us a sense of excitement and to some extent excitement [26]. When individuals focus on the positive aspect and are deemed as being psychological fit and considered well matured or in other words psychologically well their attention is on positive relationships with others, autonomy, purpose in life, but even they succumbed to self-disclosure [27]. Thus, enabling us to draw up on our hypothesis that Psychological well-being further mediates the relationship between social network addiction and self-disclosure.

H1: Psychological well-being mediates the relationship between SNS addiction and self-disclosure.

\subsection{The Mediating Effect of Psychological Dependence}

Almost everyone spends a lot of time online on social networking sites or browsing the internet this continuous use turns into habitual use and they can also be termed as being potentially addicts as almost certainly this continuous behaviors leads towards permanent addiction. Social Networking Sites are tools for web-based groups where individuals can generate personal public profiles, connect with real-life friends, communicate with different people and engage in communication with likeminded people where their interests are similar [28]. We also define psychological dependence on social networking sites as a habit developed by SNS addiction to satisfy themselves its a sense of gratification one receives from having a strong online social 
presence [29]. Researchers have verified that the extreme usage of new technologies particularly online social networking may be mainly addictive to the younger generation [30]. The harmful affect that they expect to experience if users are forced to do without social networking thus strengthens their unreasonable behavior, leading to a serious psychological dependence on social networks [31]. Thus this type of impact plays a significant role in increasing dependence on social networks therefore categorizing psychological dependence as a key mediator between the relationship of SNS addiction and selfdisclosure.

The usage of social networking sites have become popular to such an extreme level that you are seen as an outcast if your presence is not evident online, this phenomena has drastically increased in the western hemisphere whereas the developing world is also not an exception.i.e. Pakistan. The statistics show an alarming rate of individuals logging onto various SNS and a certain percentage have been known to use these website for continuously for a straight 24 hours. Specifically younger generations are totally dependent on social network websites such as Facebook. In the context, of social networking usage, individuals might initially attempt to maximize media usefulness through the repetitive use of social networks [32], this shows users psychological dependence enhances the relationship between SNS and selfdisclosure.

In the context of above literature, we propose that psychological dependence mediates the relationship between SNS addiction and self-disclosure.

H2: Psychological dependence mediates the relationship between SNS addiction and self-disclosure.

\subsection{The Mediating Effect of Perceived Ease of Use (PEOU)}

Social networking sites engage the users in many different ways. It lets every individual to communicate with each other and develop social relationship [33]. Perceived ease of use is the fundamental section of the technology acceptance model. In the field of information technology, the most important research model is technology acceptance model which provides help to understand the usage of information technology [34]. PEOU is defined as the level to which the habitual user thinks that the target system to be free of energy [35]. PEOU is also defined as the degree to which an individual believes that using a specific system would be effortless [36], it will be relatively low the more the user's perception is that mental or physical efforts are required during the initial adoption of a new technology. It comprises the simple practical features of social networking sites with regard to the service difficulty, the speed of learning to use the service and the mixing of the service with new technologies.

Perceived ease of use makes an important and positive impact on attitude towards social network websites. Past research has indicated that an increase of output quality and ease of use provided by social network sites would have increased the usage of social networking websites [35]. PEU represents a motivating factor of the social network sites as it helps in adoption of new technology and new platforms with relative ease. When users think that a particular system is easy to use, flexible, they understand or view the system as useful they tend to use it more [37]. The interaction with social network sites is easy, user-friendly, flexible in which case individual use social networking sites easily.

Furthermore, besides these social activities, everyone regularly exchanges messages with subtle feelings and want to reach mutual considerations. Thus, if users understand that social network sites provide the services for them to express their thoughts and feelings precisely so that others can understand them correctly and in a timely manner, then they will also think that social networks are an effective tool for socialization.

Past research has adopted the use of PEOU and individual model to explain technology usage/acceptance such as a social networks for a variety of information systems including online learning. The amount of time and purpose of using social network is dependent on one's personal qualities and related to one's opinions of technology usefulness and ease of use, and ultimately how intensely the SN platforms are being used around them in society [38].

These leads us to develop the following hypothesis for testing the mediating effect of perceived ease of use.

H3: Perceived Ease of Use mediates the relationship between SNS addiction and self-disclosure.

\subsection{The Mediating Effect of Habit}

Social networking sites allow individuals to stay connected with anyone, anywhere and from any country at any given time of day on Facebook, twitter, Instagram, Snap chat and many more. Due to flexible nature and easy use of SNS majority of peoples become habitual users of social networks and this habit leads them to spend excessive amount of time on a daily basis. This type of habit of using SNS can be called as SNS addiction as this leads towards excessive usage over long periods of time. Habits are defined as "conditionbehavior structures that are or have become automatic so that they occur without self-instruction" [39]. Habit is also defined as "a tendency to repeat responses given a stable support context" [40]. It represents the usual ways of acting and goal and environmental dependence [41]. The indications that generate habitual activities can be outside events or internal conditions that are only partially associated with the situation at hand [42].

In the viewpoint of a social networks, habit denotes to the level to which individual tends to accomplish activities such as repetitive usage of social network routinely [43]. Habitual usage patterns have been widely defined as an automatic response that is repeated in specific situations to obtain specific goals or end states [32, 44]. In the perspective of social network usage, individuals might initially effort to maximize media usefulness through the repetitive use of social networks. This shows that people are looking for rational and conscious pleasures to satisfy their social networking needs through repetitive usage behavior [32]. For 
example this has been proved in previous studies that basic reasons of using social networks is to keep contact with others, to collect important information, to check the interesting things, to read interesting posts to send information, self-disclosure, to make new friends are basic motivations which make someone habitual of social networks $[45,46]$. The habitual usage of social networks will almost certainly grow into addictive behavior [47]. Thus habit should be reflected as a basic state of SNS addiction. It means habit increases the usage of a social networking in individuals. According to psychology, habit denotes learned actions that become automatic responses to some situations, which can be useful in gaining some objectives or end-states [48]. According to some researcher, habits are generally supposed as learned sequence of deeds that become automatic responses to particular conditions, which may be beneficial in gaining certain goals or end states" [49], while some researchers claims that habits can form comparatively rapidly, sometimes simply as a result of responses [50-52]. We believe that habit is a key factor related to SNS because social networking websites play a role in augmenting users observation, which is indirectly related to habit.

It is obvious that habit mediates the relationship between SNS and self-disclosure. Based on the discussion above, we propose the following hypotheses for testing.

H4: Habit mediates the relationship between SNS addiction and self-disclosure.

\section{Research Methodology}

\subsection{Sample and Data Collection}

To examine the research model developed in this article, a survey questionnaire was developed using existing constructs but the relationships were set in order to understand the relationship between SNS addiction and self-disclosure. The sample was university students including undergraduate, graduate/masters, and doctorate research students in Pakistani universities who use social media for leisure and other professional purposes. This study, only focused on students because social media is popular especially among younger generation of Pakistan. Data collection was carried out via the internet through survey website.i.e. Google forms. To encourage response follow-up call were made on Facebook and sent reminder emails after sent out the questionnaires and continuously followed up on potential respondents. Over a period of four to five weeks, we got 388 respondents. An online version of the questionnaire was prepared, and individuals were encouraged to complete the questionnaire as a whole. Table 1 shows the demographic information of the samples.

Table 1. Sample Demographic Information.

\begin{tabular}{lll}
\hline & N & Percentage \\
\hline Gender & 338 & \\
Male & 200 & 59.2 \\
Female & 138 & 40.8 \\
Age & & \\
\hline
\end{tabular}

\begin{tabular}{lll}
\hline & N & Percentage \\
\hline 21-30 years old & 214 & 63.3 \\
31-40 years old & 114 & 33.7 \\
41-50 years old & 10 & 5 \\
Education & & \\
University - Bachelors/Undergraduate Degree & 74 & 21.9 \\
University - Masters/Graduate Degree & 207 & 61.2 \\
University - PhD/Doctoral Degree & 55 & 16.3 \\
Currently not enrolled in further education & 02 & 0.6 \\
\hline
\end{tabular}

\subsection{Measurement}

The proposed research model consisted of 6 variables. The measurement scales used in the survey were adapted from the previous literature that have been well established in their respective domains (attached in appendix A). Habit, Perceived ease of use, Psychological Dependence, SNS Addiction, Psychological Well-being, Self-disclosure. The measurement items and scales of Habit, Perceived ease of use and Psychological Dependence was adapted from [53]. The scale of SNS Addiction was adapted from [54]. The measurement scale of Psychological Well-being are adapted from [55]. The scale of Self-disclosure was adapted from [56]. However, some items were deleted because of loading issues in two different factors in the end of factor analysis. This study considered three control variables, i.e gender, age, and education. At the individual level, gender, age and educational level, are controlled which may influence student behaviour [57].

\section{Data Analysis and Results}

\subsection{Common Method Bias}

As data were perceptual and collected from university students, common method bias was a potential threat to the validity of this dataset. Accordingly, approach is followed Podsakoff and Organ (1986) to conduct Harman's one-factor test. The principal component factor analysis yielded

six factors with Eigenvalues $>1$. The largest factor merely accounted for $38 \%$ of the variance, which was below the threshold of $55.00 \%$. Results showed these factors did not account for most of the variance, which indicated the common method bias was not an issue to be concerned about in this dataset.

\subsection{Measurement Model}

Confirmatory factor analysis (CFA) was employed to assess the validity of the scales. The CFA results indicated that the fit between the measurement model and dataset was satisfactory $(\chi 2=1421.06$, d.f. $=746$, RMSEA $=0.052$, $\mathrm{PCLOSE}=0.229, \mathrm{SRMR}=0.044, \mathrm{CFI}=0.945, \mathrm{IFI}=0.946$, $\mathrm{NFI}=0.89$, and TLI $=0.94$ ). For data analysis, we calculated the validity and reliability. We also calculated the Cronbach alpha, the composite reliability of constructs, and average variance extracted (AVE) to test convergent validity. As in Table 2, Cronbach alpha ranged from 0.83 to 0.96 , was above the benchmark value of 0.70 which is suggested by [58]. The values of composite reliability ranged from 0.85 to 0.94 and 
were above the benchmark value of 0.70 which is suggested by [59]. These results indicated that the measurement model had satisfactory convergent validity. The AVE scores ranged from 0.53 to 0.70 and were above the benchmark value of 0.50 suggested by [60]. These results indicated that the measurement model had good convergent validity. In addition, as Table 3 shows, the square roots of the AVEs for all constructs were greater than the correlations between constructs, which confirmed the discriminant validity of the measurement model.

Table 2. The Results of Confirmatory Factor Analysis.

\begin{tabular}{|c|c|c|c|c|c|c|}
\hline Constructs & Items & $\mathbf{C A}$ & CR & AVE & MSV & ASV \\
\hline Perceived ease of use & 4 & 0.87 & 0.89 & 0.68 & 0.30 & 0.20 \\
\hline Psychological dependence & 8 & 0.92 & 0.93 & 0.62 & 0.43 & 0.19 \\
\hline SNS addiction & 5 & 0.87 & 0.85 & 0.53 & 0.43 & 0.21 \\
\hline Psychological well-being & 4 & 0.83 & 0.85 & 0.59 & 0.30 & 0.17 \\
\hline Habit & 3 & 0.83 & 0.87 & 0.70 & 0.26 & 0.20 \\
\hline Self-disclosure & 17 & 0.96 & 0.94 & 0.70 & 0.25 & 0.18 \\
\hline
\end{tabular}

Note: $\mathrm{CA}=$ Cranach's alpha; $\mathrm{CR}=$ composite reliability; AVE = average variance extracted; MSV= Maximum Shared Variance; AVE= Average Variance Extracted; ASV= Average Shared Variance; Discriminant validity: AVE $>$ MSV and ASV $<$ AVE.

Furthermore, we tested discriminant validity by comparing shared variances among constructs. Table 3 shows, none of the correlations between constructs was higher than the square roots of the AVE, which meets the requirement of discriminant validity. Hence, we concluded that the measurement model possessed adequate convergent validity, discriminant validity, and reliability.

Table 3. Descriptive Statistics and Interco relations Matrix of the variables.

\begin{tabular}{|c|c|c|c|c|c|c|c|c|c|c|c|}
\hline Variable & M & SD & 1 & 2 & 3 & 4 & 5 & 6 & 7 & 8 & 9 \\
\hline 1. SD & 5.3 & 1.2 & 0.83 & & & & & & & & \\
\hline 2. PWB & 5.5 & 1.0 & $0.38 * *$ & 0.76 & & & & & & & \\
\hline 3. SNSA & 5.2 & 1.3 & $0.26 * *$ & $0.37 * *$ & 0.72 & & & & & & \\
\hline 4. Habit & 5.4 & 1.4 & $0.32 * *$ & $0.43 * *$ & $0.49 * *$ & 0.83 & & & & & \\
\hline 5. PEOU & 5.5 & 1.3 & $0.34 * *$ & $0.54 * *$ & $0.41 * *$ & $0.50 * *$ & 0.82 & & & & \\
\hline 6. PD & 5.3 & 1.3 & $0.24 * *$ & $0.29 * *$ & $0.65 * *$ & $0.43 * *$ & $0.398 * *$ & 0.78 & & & \\
\hline 7. Education & NA & NA & $0.11^{*}$ & 0.01 & 0.06 & 0.03 & $0.127 *$ & 0.06 & NA & & \\
\hline 9. Gender & NA & NA & $-0.12 *$ & $-0.33 * *$ & $-0.35^{* *}$ & $-0.35^{* *}$ & $-0.36^{* *}$ & $-0.33^{* *}$ & $-0.07 * *$ & $0.01 * *$ & NA \\
\hline
\end{tabular}

**. Correlation is significant at the 0.01 level.*. Correlation is significant at the 0.05 level.

Note: $\mathrm{N}=338, \mathrm{~N} / \mathrm{A}=$ not applicable; Mean are assessed based on average factor scores; standard deviation (SD) and correlations are from the second-order CFA output. The diagonal elements are the square root of the AVE.

As shown in Table 4, all items loaded well onto their corresponding constructs and poorly onto other constructs. These test results suggested good discriminant validity. Therefore, the measurement model possessed adequate convergent validity, discriminant validity, and reliability.

Table 4. Item loadings and cross-loadings.

\begin{tabular}{|c|c|c|c|c|c|c|c|}
\hline Constructs & Item & SD & PD & PEOU & SNSA & PWB & Habit \\
\hline \multirow[t]{15}{*}{ Self-disclosure (SD) } & F01 & .906 & .029 & -.120 & .005 & .015 & .035 \\
\hline & F02 & .903 & .036 & .025 & -.085 & .041 & .013 \\
\hline & F03 & .897 & .037 & -.037 & -.067 & -.020 & .081 \\
\hline & F04 & .885 & .019 & .029 & -.036 & .025 & -.098 \\
\hline & F05 & .882 & .012 & -.027 & -.065 & .051 & .027 \\
\hline & F06 & .882 & -.014 & .068 & -.022 & .014 & -.069 \\
\hline & F07 & .881 & -.093 & .100 & .078 & -.016 & -.146 \\
\hline & F09 & .869 & .015 & .118 & -.030 & -.077 & -.042 \\
\hline & F010 & .858 & -.033 & -.005 & .080 & -.016 & .027 \\
\hline & F011 & .850 & .001 & .101 & .020 & -.038 & -.039 \\
\hline & F012 & .840 & .057 & .067 & -.067 & -.105 & .043 \\
\hline & F013 & .833 & .016 & -.148 & .035 & .028 & .164 \\
\hline & F014 & .832 & -.039 & -.078 & .047 & .008 & .122 \\
\hline & F015 & .811 & -.005 & -.013 & .117 & -.066 & .010 \\
\hline & F017 & .751 & -.058 & -.171 & .017 & .093 & .036 \\
\hline \multirow[t]{3}{*}{ Psychological Dependence (PD) } & $\mathrm{C} 01$ & -.018 & .919 & .008 & -.156 & -.021 & .066 \\
\hline & $\mathrm{C} 02$ & .037 & .885 & -.013 & -.159 & .042 & .015 \\
\hline & $\mathrm{C} 03$ & -.041 & .852 & -.054 & -.024 & .125 & .003 \\
\hline
\end{tabular}




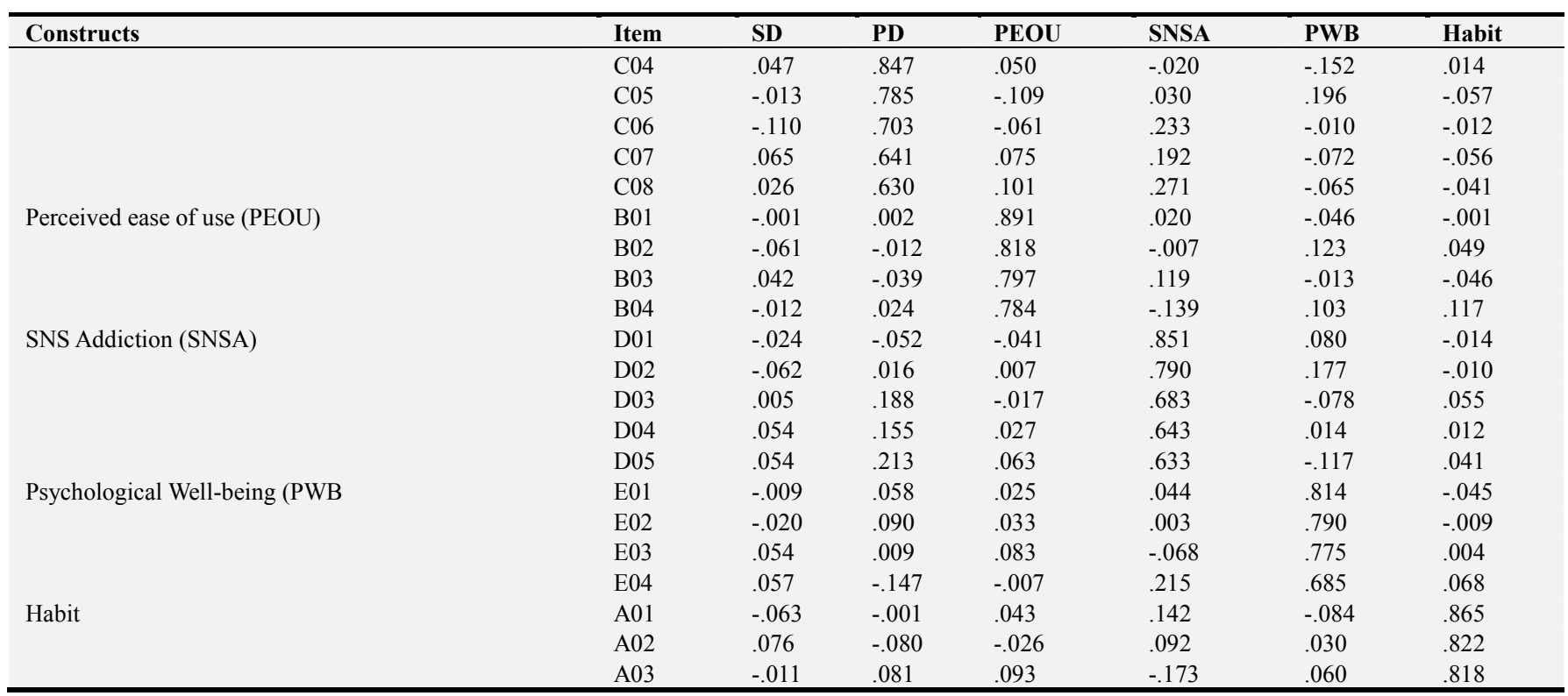

\subsection{Structural Model}

Figure 2 shows the structural model results. The structural equation model was initially used to test the hypotheses. The results confirmed that most of the hypothesis were positively significant, except the relationships between psychological dependence and self-disclosure. $(\beta=0.24, p>0.05)$. The results in structural equation model provided a precondition of most proposed mediating effects. The mediating effect proposed in $\mathrm{H} 2$ were rejected. While other mediating effect is supported in this initial level.

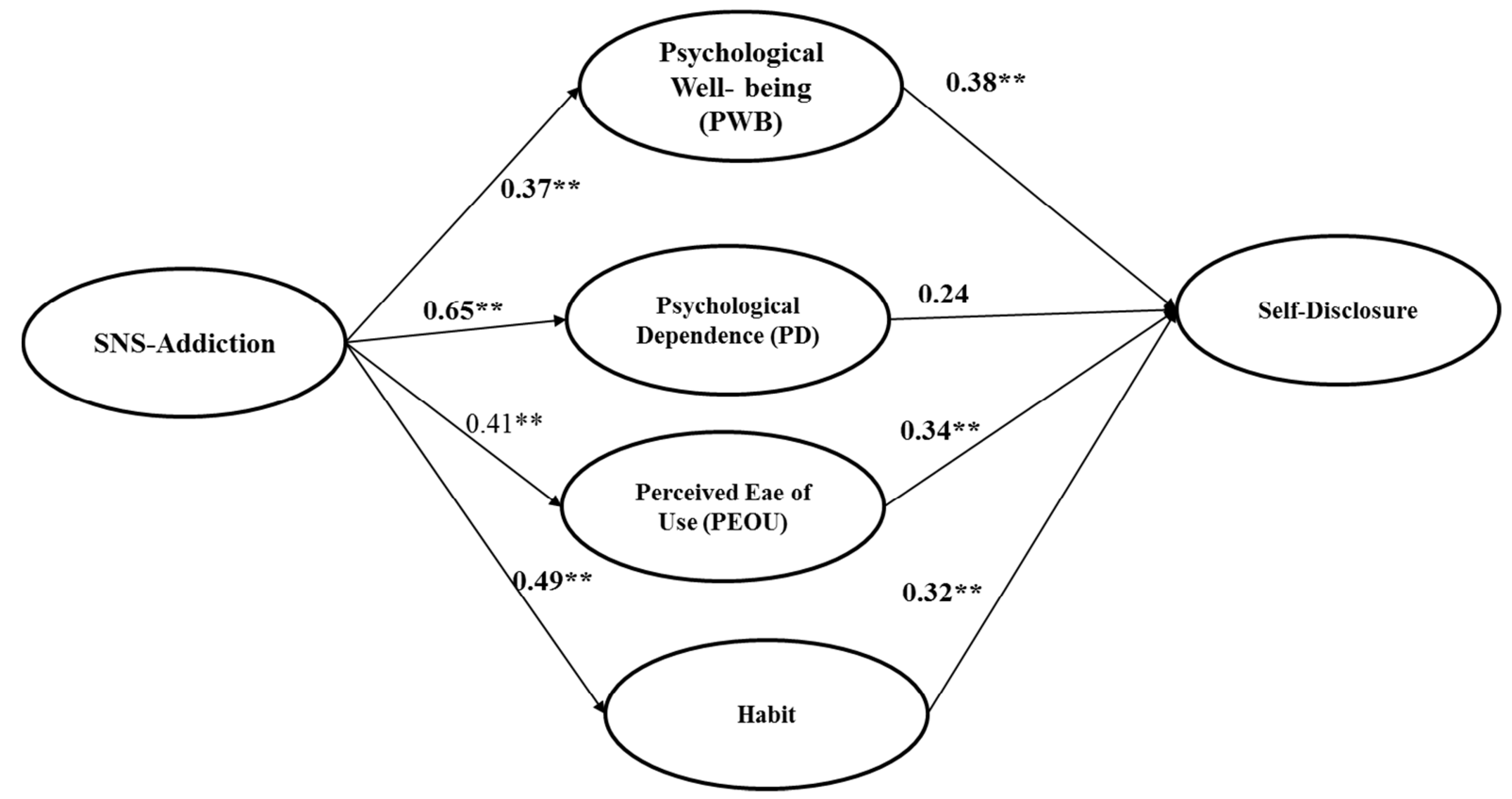

Note: * shows significance at the 0.05 level, and ** shows significance at the 0.001 level.

Figure 2. Results of the structural equation modeling.

\subsection{Mediating Effect test}

We employed two approaches to test the mediating effects of the three psychological conditions. First, we used the bootstrap sampling method (bootstrap sample size $=5000$ ) recommended by [61], to generate asymmetric confidence intervals (CIs) for the indirect relationship. Table 5 shows the results of mediating effects. Specifically, psychological wellbeing mediates the effect of SNS usage on Self-disclosure because the CI $(.481,203)$ excludes zero. H1 was supported. Psychological dependence did not mediates the relationship between SNS usage and self-disclosure because the CI $(0.0009,0.202)$ includes zero. $\mathrm{H} 2$ is rejected. Habit mediates the relationship between SNS usage and Self-disclosure because of the CL $(.0 .0533,0.2060)$ exclude zero. $\mathrm{H} 4$ also supported. Perceived Ease of Use does not mediate the relationship between SNS usage and Self-disclosure because 
CI $(0.0439,0.1772)$ exclude zero. H3 was supported.

Table 5. Results of bootstrapping method for mediation.

\begin{tabular}{|c|c|c|c|c|c|c|c|c|c|c|}
\hline & IV & $\mathbf{M}$ & DV & $\begin{array}{l}\text { Effect of IV } \\
\text { on M (a) }\end{array}$ & $\begin{array}{l}\text { Effect of M on } \\
\text { DV (b) }\end{array}$ & $\begin{array}{l}\text { Direct Effect } \\
\left(c^{\prime}\right)\end{array}$ & $\begin{array}{l}\text { Indirect Effect } \\
(\mathbf{a * b )}\end{array}$ & $\begin{array}{l}\text { Total Effect } \\
\text { (c) }\end{array}$ & $95 \% \mathrm{CI}$ & Result \\
\hline $\mathrm{H} 1$ & SNSA & PWB & SD & $0.290 * *$ & $0.364 * *$ & $0.143^{*}$ & $0.105^{* *}$ & $0.249 * *$ & $(0.481,0.203)$ & Supported \\
\hline $\mathrm{H} 2$ & SNSA & PD & SD & $0.634 * *$ & $0.134 * *$ & $0.163^{*}$ & $0.084 * *$ & $0.249 * *$ & $(-0.0009,0.202)$ & Un-Supported \\
\hline H3 & SNSA & PEOU & SD & $0.341 * *$ & $0.284 * *$ & $0.152 *$ & $0.096 * *$ & $0.284 * *$ & $(0.0439,0.1772)$ & Supported \\
\hline $\mathrm{H} 4$ & SNSA & Habit & SD & $0.443 * *$ & $0.259 * *$ & $0.133 *$ & $0.114 * *$ & $0.249 * *$ & $(0.0533,0.2060)$ & Supported \\
\hline
\end{tabular}

Note: * shows significance at the 0.05 level, and ** shows significance at the 0.01 level.

We used the method suggested by Baron and Kenny (1986) to test whether the supported mediating effects were full or partial. Three kinds of relationships are significant for a valid mediating effect: (1) the relationship between independent variable and dependent variable, (2) the relationship between independent variable and mediator, and (3) the relationship between mediator and dependent variable controlled by the independent variable. If the relationship between independent variable and dependent variable controlled by mediator is insignificant, the mediating effect is fully mediated. Otherwise, it is partially mediated. Table 6 shows the results of the Baron and Kenny mediation test, which supported most of the hypotheses except H2. This result is consistent with that of the bootstrapping mediation test, indicating the robustness of the hypothesis testing.

Table 6. Results of the Baron and Kenny method for mediation.

\begin{tabular}{|c|c|c|c|c|c|c|c|c|}
\hline & \multirow[b]{2}{*}{ IV } & \multirow[b]{2}{*}{ M } & \multirow[b]{2}{*}{ DV } & \multirow[b]{2}{*}{ IV-DV } & \multirow[b]{2}{*}{ IV-M } & \multicolumn{2}{|c|}{ IV+M-DV } & \multirow[b]{2}{*}{ Mediation } \\
\hline & & & & & & IV-DV & M-DV & \\
\hline H1 & SNSA & PWB & SD & $0.274 * *$ & $0.377 * *$ & $0.140^{*}$ & $0.354 * *$ & Partial \\
\hline $\mathrm{H} 2$ & SNSA & PD & SD & $0.274 * *$ & $0.675^{* *}$ & 0.178 & 0.142 & NO \\
\hline H3 & SNSA & PEOU & SD & $0.274 * *$ & $0.411^{* *}$ & $0.147^{*}$ & $0.286^{* *}$ & Partial \\
\hline $\mathrm{H} 4$ & SNSA & Habit & SD & $0.274 * *$ & $0.527 * *$ & $0.137^{*}$ & $0.258 * *$ & Partial \\
\hline
\end{tabular}

Note: * shows significance at the 0.05 level, and ** shows significance at the 0.01 level.

\section{Discussion and Future Directions}

\subsection{Discussion}

The purpose of this research is to investigate the mediating effect of habit, psychological well-being, psychological dependence, preserved ease of use between SNS and Selfdisclosure. This study empirically investigated the value of SNS by untangling how to improve self-disclosure via using SNS. The mediating effects of habit, perceived ease of use, psychological well-being and psychological dependence are hypothesized and tested. From our hypotheses three are supported and 1 is unsupported.

The results of this study show that, psychological dependence of use cannot mediate the effect of SNS on selfdisclosure. The possible reason is that survey is online, may be students did not understand the nature of question. All the variables has partial effect on self-disclosure. The possible reason is that perceived ease of use is related to technology and this explain how technology is easy for users, as the data collected was from university students that are all already familiar with various technologies. SNS usage is easy for younger generations specifically for students. The findings give an insight into the mediating effect of two key constructs that are evident in research in social networks. Both Psychological well-being and psychological dependence resonate from the usage of social networking websites. As online socializing may not be face-to-face communication but it does give every individual a sense of belonging and being heard. Being heard creates the dependence factor that will lead towards psychological wellbeing, however excessive dependence may be a triggering factor and may lead towards addiction. An attempt was made to highlight a crucial factor that in the days before SNS and internet social life existed in face-to-face communication whereas in these recent times socializing almost certainly involves becoming a regular user of SNS. This behaviour can result in unintentional and intentional disclosure without understanding the consequences.

\subsection{Future Directions}

This study is among a very few conducted in the developing world or for that matter in Pakistan. The future directions could include a longitudinal study whereas individuals could be informed about self-disclosure and its consequences and then regularly assessed on the basis of how they adjust their behavior over time. Data was collected using random sample method whereas snow balling was also used to a certain extent with constant follow-up, another way would be to collect data from not only tier 1 cities in Pakistan but also secondary and tertiary cities as that could yield more results. Another link could be tested with self-disclosure and literacy rate, whereas the developed countries have policies in place the developing world is only just starting to under the potential of SNS. The role of trust could also be tested as on SNS people tend to trust others quickly, whereas the individual remains faceless, these risky behaviours can lead towards serious consequences. Finally one other direction could be to study the social networking sites (SNS) or rather social media policy in effect 
in Pakistan and compare it to the policy of western developed nations. Whereas the developed world has separate departments looking into white collar and social crimes the developing world seldom is anyone prosecuted in the court of law due to lack of legislation available to convict or lack of procedure to hold trial. This study was relatively simple and straight forward in highlighting the factors leading towards self-disclosure behavior, future studies could also examine complex factors that lead towards excessive usage and also self-disclosure behavior.

\section{Appendix}

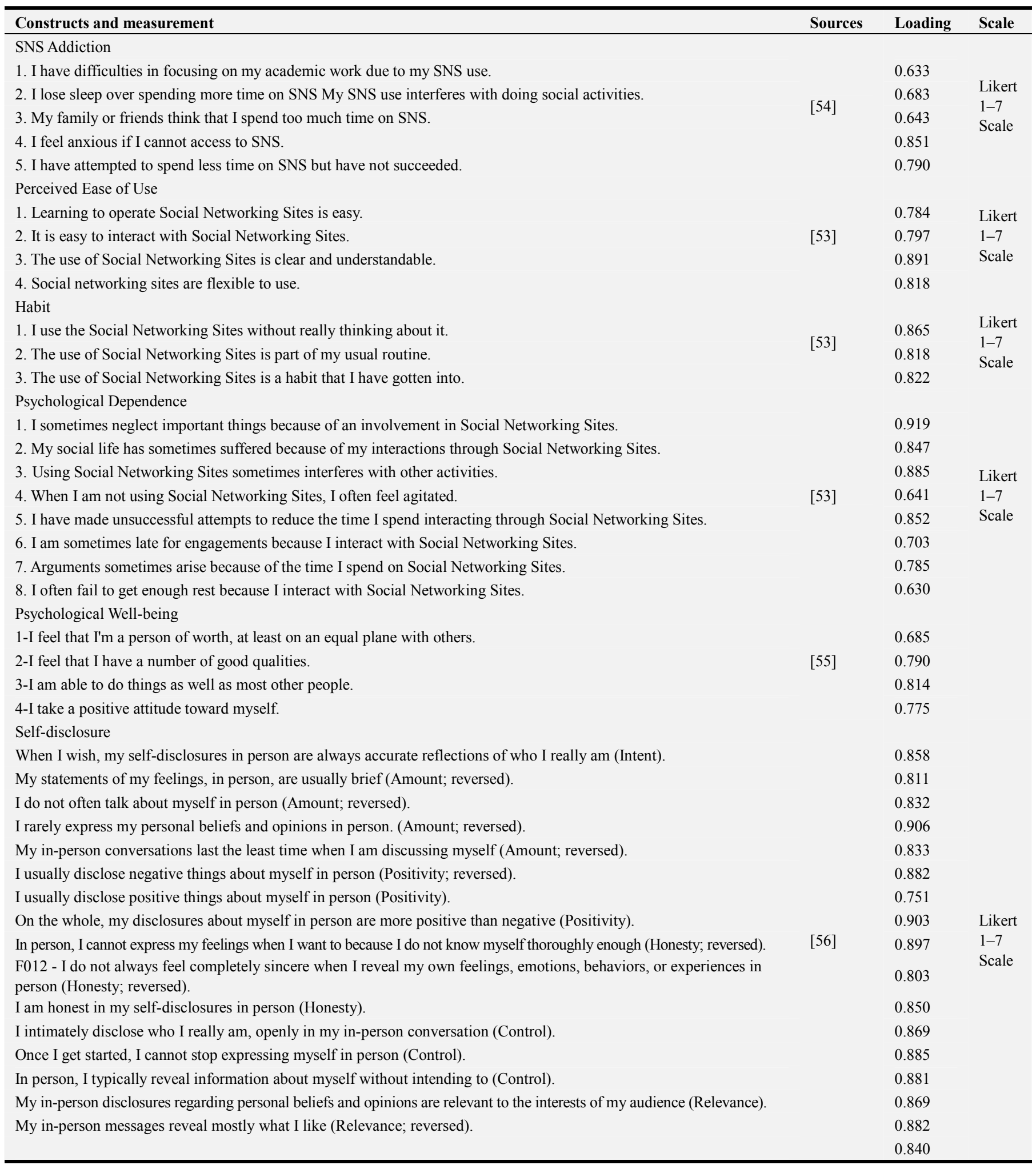




\section{References}

[1] D. Seo and J. Lee, "Web_2. 0 and five years since: How the combination of technological and organizational initiatives influences an organization's long-term Web_2. 0 performance," Telematics and Informatics, vol. 33, pp. 232-246, 2016.

[2] L. Can and N. Kaya, "Social Networking Sites Addiction and the Effect of Attitude towards Social Network Advertising," Procedia-Social and Behavioral Sciences, vol. 235, pp. 484492, 2016.

[3] T. O'Reilly, "Web 2.0 compact definition: Trying again. Radar," ed, 2006.

[4] A. M. Kaplan and M. Haenlein, "Users of the world, unite! The challenges and opportunities of Social Media," Business horizons, vol. 53, pp. 59-68, 2010.

[5] P. M. Leonardi, M. Huysman, and C. Steinfield, "Enterprise social media: Definition, history, and prospects for the study of social technologies in organizations," Journal of Computer - Mediated Communication, vol. 19, pp. 1-19, 2013.

[6] R. Lin and S. Utz, "Self-Disclosure on SNS: Do Disclosure Intimacy and Narrativity Influence Interpersonal Closeness and Social Attraction?," Computers in Human Behavior, 2017.

[7] I. Altman and D. A. Taylor, Social penetration: The development of interpersonal relationships: Holt, Rinehart \& Winston, 1973.

[8] K. F. Hew, "Students' and teachers' use of Facebook," Computers in Human Behavior, vol. 27, pp. 662-676, 2011.

[9] K. T. Li-Barber, "Self-disclosure and student satisfaction with Facebook," Computers in Human behavior, vol. 28, pp. 624630, 2012.

[10] N. J. Hum, P. E. Chamberlin, B. L. Hambright, A. C. Portwood, A. C. Schat, and J. L. Bevan, "A picture is worth a thousand words: A content analysis of Facebook profile photographs," Computers in Human Behavior, vol. 27, pp. 1828-1833, 2011.

[11] I. Ahmed and T. F. Qazi, "Deciphering the social costs of Social Networking Sites (SNSs) for university students," African Journal of Business Management, vol. 5, p. 5664, 2011.

[12] R. A. Elphinston and P. Noller, "Time to face it! Facebook intrusion and the implications for romantic jealousy and relationship satisfaction," Cyberpsychology, Behavior, and Social Networking, vol. 14, pp. 631-635, 2011.

[13] T. Akter and G. E. Nweke, "Social media users and their social adaptation process in virtual environment: Is it easier for Turkish Cypriots to be social but virtual beings?," Computers in Human Behavior, vol. 61, pp. 472-477, 2016.

[14] D. Boyd and N. Ellison, "Social network sites: definition, history, and scholarship," IEEE Engineering Management Review, vol. 3, pp. 16-31, 2010.

[15] H. Liu, "Social network profiles as taste performances," Journal of Computer - Mediated Communication, vol. 13, pp. 252-275, 2007.

[16] K. Lewis, J. Kaufman, M. Gonzalez, A. Wimmer, and N. Christakis, "Tastes, ties, and time: A new social network dataset using Facebook. com," Social networks, vol. 30, pp. 330-342, 2008.

[17] L. R. Wheeless and J. Grotz, "Conceptualization and measurement of reported self-disclosure," Human Communication Research, vol. 2, pp. 338-346, 1976.

[18] N. L. Collins and L. C. Miller, "Self-disclosure and liking: a meta-analytic review," Psychological bulletin, vol. 116, p. 457, 1994.

[19] J. A. Johnson, "Personality Tests: Self-Disclosures or SelfPresentations?," 1980.

[20] C. D. Ryff, "Happiness is everything, or is it? Explorations on the meaning of psychological well-being," Journal of personality and social psychology, vol. 57, p. 1069, 1989.

[21] R. M. Ryan and E. L. Deci, "On happiness and human potentials: A review of research on hedonic and eudaimonic well-being," Annual review of psychology, vol. 52, pp. 141166, 2001.

[22] E. Diener, S. Oishi, and R. E. Lucas, "Subjective well-being: The science of happiness and life satisfaction," Oxford handbook of positive psychology, vol. 2, pp. 187-194, 2009.

[23] F.-Y. Hong, D.-H. Huang, H.-Y. Lin, and S.-L. Chiu, "Analysis of the psychological traits, Facebook usage, and Facebook addiction model of Taiwanese university students," Telematics and Informatics, vol. 31, pp. 597-606, 2014.

[24] K. T. Kwak, S. K. Choi, and B. G. Lee, "SNS flow, SNS selfdisclosure and post hoc interpersonal relations change: Focused on Korean Facebook user," Computers in Human Behavior, vol. 31, pp. 294-304, 2014.

[25] K. N. Hampton, L. S. Goulet, C. Marlow, and L. Rainie, "Why most Facebook users get more than they give," Pew Internet \& American Life Project, vol. 3, pp. 1-40, 2012.

[26] M. Burke, C. Marlow, and T. Lento, "Social network activity and social well-being," in Proceedings of the SIGCHI conference on human factors in computing systems, 2010, pp. 1909-1912.

[27] S. B. Choi and M. S. Lim, "Effects of social and technology overload on psychological well-being in young South Korean adults: The mediatory role of social network service addiction," Computers in Human Behavior, vol. 61, pp. 245-254, 2016.

[28] D. J. Kuss and M. D. Griffiths, "Online social networking and addiction - a review of the psychological literature," International journal of environmental research and public health, vol. 8, pp. 3528-3552, 2011.

[29] J. Wright, The soft addiction solution: Break free of the seemingly harmless habits that keep you from the life you want: Penguin, 2006.

[30] E. Echeburúa and P. de Corral, "Addiction to new technologies and to online social networking in young people: A new challenge," ed, 2009.

[31] C. Wang, M. K. Lee, and Z. Hua, "A theory of social media dependence: Evidence from microblog users," Decision Support Systems, vol. 69, pp. 40-49, 2015.

[32] R. LaRose, C. A. Lin, and M. S. Eastin, "Unregulated Internet usage: Addiction, habit, or deficient self-regulation?," Media Psychology, vol. 5, pp. 225-253, 2003. 
[33] B. Sago, "Factors influencing social media adoption and frequency of use: An examination of Facebook, Twitter, Pinterest and Google+," International Journal of Business and Commerce, vol. 3, pp. 1-14, 2013.

[34] P. Y. Chau, "Influence of computer attitude and self-efficacy on IT usage behavior," Journal of Organizational and End User Computing, vol. 13, p. 26, 2001.

[35] F. D. Davis, R. P. Bagozzi, and P. R. Warshaw, "User acceptance of computer technology: a comparison of two theoretical models," Management science, vol. 35, pp. 982-1003, 1989.

[36] E. Karahanna and D. W. Straub, "The psychological origins of perceived usefulness and ease-of-use," Information \& management, vol. 35, pp. 237-250, 1999.

[37] F. D. Davis, "Perceived usefulness, perceived ease of use, and user acceptance of information technology," MIS quarterly, pp. 319-340, 1989.

[38] M. Lane and P. Coleman, "Technology ease of use through social networking media," Journal of Technology Research, vol. 3, p. 1, 2012.

[39] H. C. Triandis, "Values, attitudes, and interpersonal behavior," in Nebraska symposium on motivation, 1979.

[40] J. A. Ouellette and W. Wood, "Habit and intention in everyday life: The multiple processes by which past behavior predicts future behavior," Psychological bulletin, vol. 124, p. 54, 1998.

[41] D. Thadani and C. Cheung, "Exploring the role of online social network dependency in habit formation," 2011.

[42] W. Wood and D. T. Neal, "A new look at habits and the habitgoal interface," Psychological review, vol. 114, p. 843, 2007.

[43] M. Limayem, S. G. Hirt, and C. M. Cheung, "How habit limits the predictive power of intention: The case of information systems continuance," MIS quarterly, pp. 705-737, 2007.

[44] M. Limayem and C. M. Cheung, "Understanding information systems continuance: The case of Internet-based learning technologies," Information \& management, vol. 45, pp. 227232, 2008.

[45] G. Chen, P. N. Sharma, S. K. Edinger, D. L. Shapiro, and J.-L. Farh, "Motivating and demotivating forces in teams: crosslevel influences of empowering leadership and relationship conflict," Journal of Applied Psychology, vol. 96, p. 541, 2011.

[46] D. Zhao and M. B. Rosson, "How and why people Twitter: the role that micro-blogging plays in informal communication at work," in Proceedings of the ACM 2009 international conference on Supporting group work, 2009, pp. 243-252.
[47] B. J. Everitt and T. W. Robbins, "Neural systems of reinforcement for drug addiction: from actions to habits to compulsion," Nature neuroscience, vol. 8, pp. 1481-1489, 2005.

[48] C. L. Hull, "Principles of behavior: An introduction to behavior theory," 1943.

[49] B. Verplanken, H. Aarts, A. Knippenberg, and A. Moonen, "Habit versus planned behaviour: A field experiment," British journal of social psychology, vol. 37, pp. 111-128, 1998.

[50] W. Thorngate, "Must we always think before we act?," Personality and Social Psychology Bulletin, vol. 2, pp. 31-35, 1976.

[51] H. Triandis, "Interpersonal Behavior (Brooks/Cole, Monterey, CA)," Google Scholar, 1977.

[52] J. Watson, "Behavior: An introduction to comparative behavior," New York: Holt, 1914.

[53] J. P. Charlton, "A factor - analytic investigation of computer 'addiction'and engagement," British journal of psychology, vol. 93, pp. 329-344, 2002.

[54] M. Koc and S. Gulyagci, "Facebook addiction among Turkish college students: the role of psychological health, demographic, and usage characteristics," Cyberpsychology, Behavior, and Social Networking, vol. 16, pp. 279-284, 2013.

[55] C. Steinfield, N. B. Ellison, and C. Lampe, "Social capital, self-esteem, and use of online social network sites: A longitudinal analysis," Journal of Applied Developmental Psychology, vol. 29, pp. 434-445, 2008.

[56] L. R. Wheeless and J. Grotz, "The measurement of trust and its relationship to self - disclosure," Human Communication Research, vol. 3, pp. 250-257, 1977.

[57] N. Madjar and G. R. Oldham, "Task rotation and polychronicity: Effects on individuals' creativity," Human Performance, vol. 19, pp. 117-131, 2006.

[58] T. R. Hinkin, "A brief tutorial on the development of measures for use in survey questionnaires," Organizational research methods, vol. 1, pp. 104-121, 1998.

[59] J. C. Nunnally and I. Bernstein, "Validity," Psychometric theory, pp. 99-132, 1994.

[60] R. P. Bagozzi and Y. Yi, "On the evaluation of structural equation models," Journal of the academy of marketing science, vol. 16, pp. 74-94, 1988.

[61] D. P. MacKinnon, C. M. Lockwood, and J. Williams, "Confidence limits for the indirect effect: Distribution of the product and resampling methods," Multivariate behavioral research, vol. 39, pp. 99-128, 2004. 